This item was submitted to Loughborough's Research Repository by the author.

Items in Figshare are protected by copyright, with all rights reserved, unless otherwise indicated.

\title{
Application of clinical imaging and 3D printing to the identification of anomalies in an ancient Egyptian animal mummy
}

PLEASE CITE THE PUBLISHED VERSION

https://doi.org/10.1016/j.jasrep.2015.06.028

PUBLISHER

Elsevier

VERSION

AM (Accepted Manuscript)

\section{PUBLISHER STATEMENT}

This work is made available according to the conditions of the Creative Commons Attribution-NonCommercialNoDerivatives 4.0 International (CC BY-NC-ND 4.0) licence. Full details of this licence are available at: https://creativecommons.org/licenses/by-nc-nd/4.0/

\section{LICENCE}

CC BY-NC-ND 4.0

\section{REPOSITORY RECORD}

McKnight, Lidija M., Judith E. Adams, Andrew Chamberlain, Stephanie D. Atherton-Woolham, and Richard Bibb. 2015. "Application of Clinical Imaging and 3D Printing to the Identification of Anomalies in an Ancient Egyptian Animal Mummy". Loughborough University. https://hdl.handle.net/2134/18695. 


\title{
Application of Clinical Imaging and 3D Printing to the Identification of Anomalies in an
}

\section{Ancient Egyptian Animal Mummy}

\author{
Lidija M. McKnight ${ }^{\mathrm{a}}$, Judith E. Adams ${ }^{\mathrm{b}}$, Andrew Chamberlain ${ }^{\mathrm{c}}$, \\ Stephanie D. Atherton-Woolham ${ }^{\mathrm{d}}$, and Richard Bibb ${ }^{\mathrm{e}}$ \\ ${ }^{\mathrm{a}, \mathrm{c}, \mathrm{d}} \mathrm{KNH}$ Centre for Biomedical Egyptology, Faculty of Life Sciences, \\ University of Manchester, UK \\ lidija.mcknight@manchester.ac.uk,stephanie.woolham@manchester.ac.uk, \\ andrew.chamberlain@manchester.ac.uk \\ ${ }^{\mathrm{b}}$ Radiology, Royal Infirmary, Central Manchester University Hospitals NHS Foundation \\ Trust and Manchester Academic Health Science Centre, Manchester, UK \\ judith.adams@manchester.ac.uk \\ ${ }^{\mathrm{e}}$ Loughborough Design School, Loughborough University, UK \\ R.J.Bibb@lboro.ac.uk
}

Corresponding author - Lidija M. McKnight, lidija.mcknight@manchester.ac.uk

\begin{abstract}
Non-destructive assessment of wrapped mummified animal remains from ancient Egypt using imaging techniques is the most ethically viable manner by which to investigate bundle contents. Bundles studied to date revealed complete and incomplete animal skeletons, multiple individuals (or parts thereof) wrapped together in one bundle, non-skeletal material, organic matter and anomalies of unknown origin. The identification of animal species using imaging alone can be fraught with difficulty, especially in cases in which the skeleton is incomplete and diagnostic elements are lost or significantly damaged.
\end{abstract}


This paper describes the radiographic investigation of a mummy bundle wrapped in the form of a canid, a species closely associated with ancient Egyptian embalming deities. Computed tomography (CT) was performed, and the bundle contents were computer modelled, leading to the production of a laser sintered 3D replica.

Imaging identified three skeletal fragments carefully positioned to act as structural support for the bundle; however, radiographic data proved inadequate to enable definitive identification of these elements. 3D printing enabled direct comparison with skeletal reference collections and confirmed that the bones were of human origin.

This paper demonstrates that imaging of wrapped animal mummy bundles and 3D printing of unidentified elements or non-skeletal anomalies will assist in their accurate identification in a non-destructive manner.

\section{Keywords}

Radiography, computed tomography, animal mummy, 3D printing, Egypt

\section{Highlights}

- A wrapped mummy bundle from ancient Egypt was imaged using clinical radiography

- Unusual skeletal contents were revealed

- Clinical imaging proved inadequate for accurate identification of the skeletal remains

- Bones of known species were imaged for comparative purposes

- 3D printing provided positive identification of a human humerus 


\section{Introduction}

\subsection{Applications of 3D printing}

Virtual reconstruction and three-dimensional printing are emerging tools in clinical practice (Chia and Wu 2015; Lv et al. 2015; Murphy and Atala 2014; Schievano et al. 2007) and their implementation is gaining momentum in other disciplines. The study of cultural artefacts, where destructive analysis is generally not permitted, can benefit greatly from the use of noninvasive imaging and increased visualisation made possible by such techniques (Niven et al. 2009; Schilling et al. 2013; Spring and Peters 2014). The results of such analysis have important implications for the display of wrapped mummified material, the contents of which cannot be directly observed (Du Plessis et al. 2015).

\subsection{History of mummy studies}

Destructive autopsies of Egyptian mummies were popular spectacles during the eighteenth and nineteenth centuries and provided the only available method by which to determine the contents of wrapped mummy bundles at the time (Blumenbach 1794; Moschenska 2013). Animal mummies were amongst the first artefacts upon which radiographic techniques were tested in the 1890s (Glasser 1933), although imaging by radiography and computed tomography (CT) is now widely applied in the study of mummified human and animal remains (D’Auria and Marx 1988; Hoffman et al. 2002; Ikram and Iskander 2002; Jackowski et al. 2008; McKnight 2010; McKnight and Atherton-Woolham 2015; McKnight et al. in press; Moodie 1931; Raven and Taconis 2005; Vanlathem 1983; Wade et al. 2012). The ability of imaging to assess the contents of wrapped mummy bundles whilst maintaining their integrity has ensured its place as the preferred investigative tool. 


\subsection{Animal mummies as votive offerings}

Mummified animals were deposited as votive offerings in enormous numbers in ancient Egypt, acting as a physical form of 'prayer' either seeking divine assistance or in thanks to the gods to which they were dedicated (Ikram 2005; Atherton-Woolham and McKnight 2015; Taylor 2001). Catacombs containing an estimated 8 million mummies are located at the Sacred Animal Necropolis at Saqqara (Nicholson et al. 2013; Nicholson et al. 2015). The mummies recorded from the site include domestic dogs (Canis lupus familiaris), jackals (Canis aureus), foxes (Vulpes sp.), cats (Felis catus), jungle cats (Felis chaus nilotica), ichneumon (Herpestes ichneumon) and the occasional kestrel (Falco tinnunculus); indicating that other species were intentionally buried in the dog catacombs, possibly for mythological reasons (Nicholson et al. 2015).

From 2000 to 2012, 152 wrapped votive animal mummies were studied using clinical imaging to identify the contents non-destructively and to enable their classification as either true or pseudo mummies (McKnight 2010; McKnight and Atherton 2014; McKnight and Atherton-Woolham 2015; McKnight et al. 2015; McKnight et al. in press).

True mummies, those containing skeletal material, accounted for $81 \%(n=123)$ of the bundles studied. Of these, 26\% $(n=39)$ had lost their external wrappings. Of the wrapped bundles, 31\% $(n=47)$ contained a complete skeleton and $11 \%(n=17)$ contained a partial skeleton. In most cases, the species suggested by the external appearance of the bundle correlated with the contents; however, $1 \%(n=2)$ contained the remains of different species. $6 \%(n=9)$ contained the remains of more than one animal or species wrapped together in the same bundle (Atherton-Woolham and McKnight 2014). The skeletal remains were unidentifiable in $6 \%(n=9)$ of bundles. Pseudo mummies, those containing no skeletal remains, constituted the remaining $19 \%(n=29)$ of the mummy bundles investigated (McKnight et al. in press; McKnight and Atherton-Woolham 2015). The presence of pseudo 
mummies is previously reported (Ikram and Iskander 2002; Ikram 2005; McKnight 2010; von den Driesch et al. 2006); however, this study presents the first published dataset incorporating quantitative analysis on animal mummies from multiple museum collections (McKnight et al. in press).

\subsection{Species identification}

The identification of mummified animal remains to taxa and species level using imaging was sometimes difficult, in particular, where diagnostic skeletal elements were absent or incomplete and in birds where morphological variation is slight. Two-dimensional radiographs, limited by magnification and superimposition of structures within a mummy bundle, made comparison of elements with reference material problematic. CT eliminated these issues and enabled accurate measurements for skeletal elements to be obtained. This was only feasible when diagnostic elements were present and clearly identifiable. The desiccated nature of mummified soft tissue further complicated visualisation as the X-ray density was similar to bone (McKnight et al. in press).

3D printing has potential in the field of mummy studies (Bibb et al. 2015; Hoppa et al. 2006), in particular in the visualisation of skeletal and anomalous inclusions within wrapped mummy bundles. Furthermore, the technique is applicable as an interpretive medium for display purposes (Du Plessis et al. 2015; Taylor and Antoine 2014).

This manuscript presents the results of the radiographic investigation of a mummified bundle which demonstrated unexpected contents. Through the application of clinical imaging combined with 3D printing technology, these anomalies were investigated and replicated, both visually and materially, allowing an identification to be made. 


\section{Materials and Methods}

\subsection{The case study}

A wrapped mummy bundle (accession number TWCMS: 2001.406, Sunderland Museum, Tyne and Wear, UK) measuring 180 x 77 x 63mm at the widest point, was recorded in museum archives as containing the remains of a jackal. There was an external stylised appearance of a jackal and an attempt at decoration crudely formed from four bands of coloured linen (Fig. 1). No provenance regarding the Egyptian origin of the bundle was recorded.

Figure 1 - Photograph of mummy bundle TWCMS: 2001.406, stated in museum records to be the mummified remains of a jackal. The bundle had an unusually crude appearance, decorated with four horizontal linen bands. Photograph by Alex Croom.

\subsection{Imaging}

The bundle was imaged at the Manchester Royal Infirmary in March 2011 to ascertain the contents and determine its authenticity. Digital radiography (DR) was performed on Siemens YSIO Fluorospot Compact equipment (Siemens Healthcare, Erlangen, Germany) with an 
exposure of $57 \mathrm{kV}, 1 \mathrm{mAs}$ and a focal spot size of $0.6 \mathrm{~mm}$. CT was performed using a General Electric LightSpeed 64-row spiral multi-detector (MDCT) scanner (GE, Milwaukee, USA) using $120 \mathrm{kVp}$, 200mAs with a pitch of 0.969:1.

Skeletal elements from a domestic canid (C. lupus familiaris) and a baboon (namely Papio hamadryas), both known to have been mummified by the ancient Egyptians (Ikram 2013; Ikram et al. 2013; von den Driesch 2004), were imaged during 2013 for comparative purposes, together with human long bones from the University of Manchester anatomical teaching collections. DR was conducted using Philips Eleve Digital Diagnostic equipment (Philips Medical systems, Best, Netherlands) with an exposure of $57 \mathrm{kV}, 1 \mathrm{mAs}$ and a focal spot size of $0.6 \mathrm{~mm}$. CT scans were obtained in the Radiology Department of the Royal Manchester Children’s Hospital using a Siemens Somatom Definition AS+128-row MDCT scanner (Siemens Healthcare, Erlangen, Germany) at a slice thickness of 0.625mm and pitch of 0.969:1.

\subsection{Data segmentation}

CT images obtained in Digital Imaging and Communications in Medicine (DICOM) format were used to build a 3D print of the skeletal elements in the mummy bundle with the aim of improving visualisation and enabling an accurate identification. The CT images were segmented (Bibb et al. 2015) to isolate the bones by setting upper and lower CT number threshold values using specialist software (InVesalius, version 3, http://svn.softwarepublico.gov.br/trac/invesalius). The data relating to the largest single volume within that threshold range were generated as a three-dimensional computer model. These data were then translated and exported in the commonly used STL file format suitable for 3D printing. An initial model was made of the bones in their mummified position. A second model with the smaller transverse bones removed was achieved by manually editing 
the segmented image data in InVesalius. In addition, a physical replica of a reference human bone was made, scaled to be in approximate relation to the mummy bones.

The replicas were built at Loughborough University using laser sintering (Bibb et al. 2015) with a layer thickness of $0.1 \mathrm{~mm}$ (EOS P100 Formiga, EOS GmbH, Krailing, Germany) and polyamide material (EOS PA2200) resulting in an accurate and robust physical model that could be handled easily. 3D computer models were created from the DICOM data of the comparative material, although physical models were not built in this case.

\section{Results}

Imaging (radiographs and CT) revealed three fragmented skeletal elements inconsistent in appearance with those of a canid species. The larger element (measuring $175 \mathrm{~mm}$ in length, $28 \mathrm{~mm} \times 19 \mathrm{~mm}$ at proximal end and $15 \mathrm{~mm} \times 12 \mathrm{~mm}$ at distal end) was placed along the full length of the mummy bundle. The thickness of the cortical bone was $5.3 \mathrm{~mm}$ at its greatest point (mid-shaft). Two smaller elements (measuring 66mm x $9.8 \mathrm{~mm}$ x $4.5 \mathrm{~mm}$ and $56 \mathrm{~mm} \mathrm{x}$ $8 \mathrm{~mm} \times 3.8 \mathrm{~mm}$ respectively) were positioned at right angles to the primary element to form the snout and provide structural support (Fig. 2a and b). CT revealed a multi-stage wrapping method (Fig. 3a) and the cross-sectional shape of the bone struts, which appeared straight in the long axis (Fig. 3b). In addition, it showed that the ears appeared to be constructed from longitudinal structures, most probably reeds or sticks, around which linen was wrapped (Fig. 3b). The epiphyseal regions were absent from the primary element, likely lost prior to mummification at the time of fracture, making preliminary assessment difficult. Initial interpretation by clinicians and zoologists suggested that the primary element was most likely to be of human origin. 

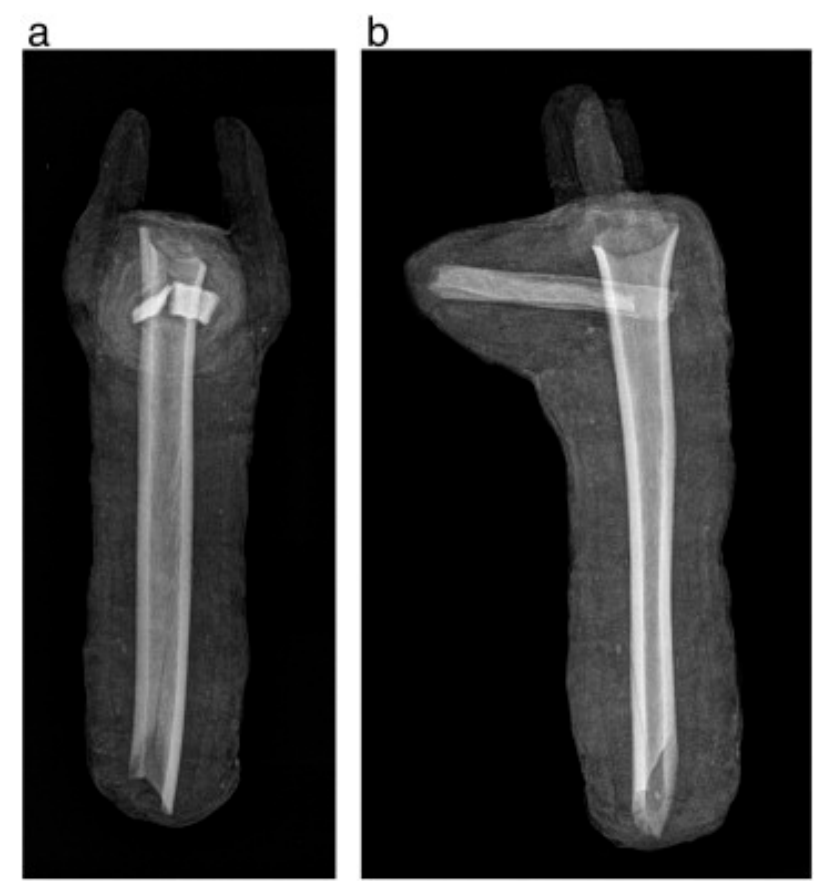

Figure 2 - Radiographs - a) Anterior-posterior radiograph and b) Lateral radiograph of mummy bundle TWCMS: 2001.406 demonstrated the presence of three fragmented skeletal elements. The primary element, now confirmed to be the shaft of a human humerus, was positioned along the length of the bundle. Two smaller elements, possibly longitudinal shards from the shaft of a long bone, were placed at right angles to either side of the primary element.

3D modelling (Fig. 4a) and replication (Fig. 4b) of the elements enabled direct comparison with osteological and zooarchaeological reference collections in the Faculty of Life Sciences, University of Manchester, and the Department of Archaeology, University of Sheffield. Animal species known to have been mummified by the ancient Egyptians were inconsistent in size, cortical thickness (canids) and robust form (primates) with the primary element in the mummy bundle. Modern human specimens, namely the left humerus, provided the closest match, particularly in the appearance of the intertubercular groove (sulcus) (Fig. 5). The two smaller transverse elements were originally postulated to be fragments of rib; however, analysis of the 3D replica suggested that the cortical thickness and shape was more consistent with longitudinal shards from a human long bone. Identification beyond this was not possible. 


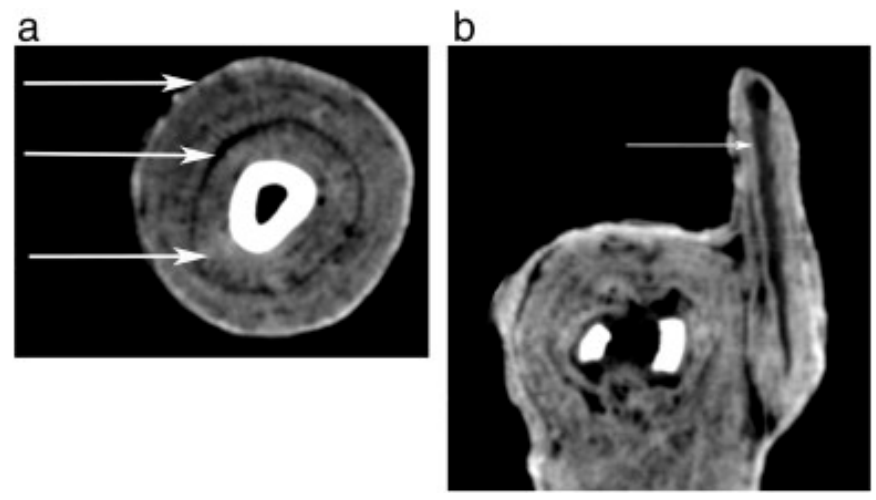

Fig. 3 - CT — a) CT transverse axial image through the bundle highlighted the presence of three different phases (marked with arrows): firstly, immediately adjacent to the skeletal element is a tightly applied, uniform linen layer; the next layer appears less compressed resulting in an air-filled void around the first linen layer; the final layer, appears radiodense, possibly the result of an exterior coating of a resinous or pigmented substance; b) the cross-sectional shape of the bone struts (which appeared straight in the long axis) and the presence of longitudinal structures of unknown origin, positioned to form the false ears (arrow).


Figure $4-$ a) Three-dimensional computer model of the skeletal contents of the mummy bundle created following the segmentation process of the DICOM data; b) Three-dimensional physical model of the skeletal contents of the mummy bundle created by laser sintering. 


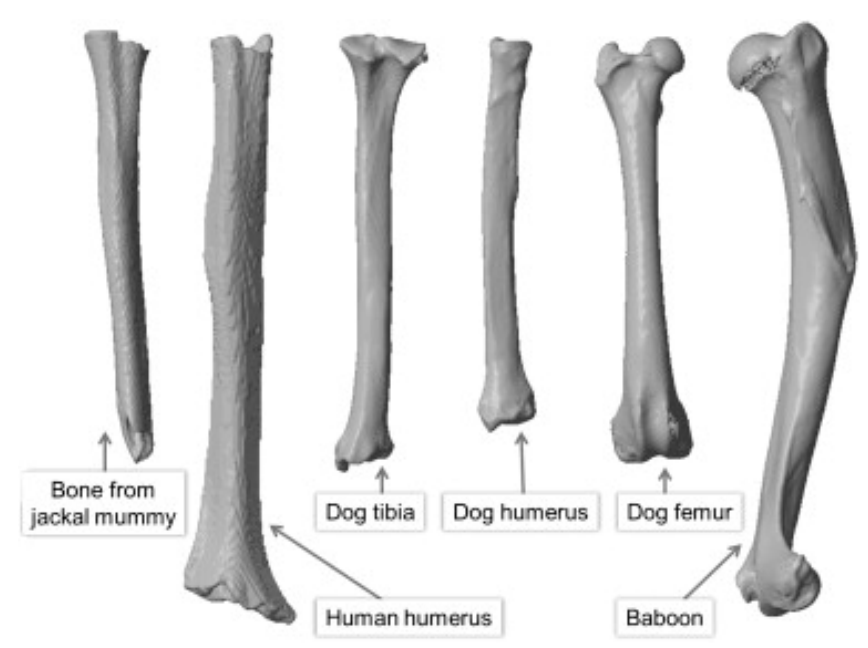

Figure 5 - Left to right - Comparison of the bone from the mummy bundle with the archaeological human humerus, canine long bones (tibia, humerus and femur), and baboon radius. The alignment of the intertubercular groove (sulcus) confirmed the identification of the mummy bone as human.

The ancient mummy humerus displayed an irregular transverse fracture through the surgical neck, and lacked the proximal part of the humerus (the head and the tuberosities). This fracture pattern, through the thin cortical bone of the neck of the humerus, is common in clinical and archaeological cases. At the distal end of the shaft, where the cortical bone is thicker, the mummy humerus exhibited a spiral fracture. This indicated that the bone was relatively fresh (i.e. with high collagen content) at the time of occurrence, implying that it happened soon after death. The small and slender appearance suggests that the individual from which it originated was most likely an adolescent female.

\section{Discussion}

The ancient Egyptians believed that canids, namely jackals, were associated with embalming deities. They are often depicted in Egyptian art in composite forms with human bodies and jackal heads (Taylor 2001), or as standing or crouched canines (Osborn and Osbornova 1998). Catacombs containing many thousands of mummified votive canids have been located at Saqqara and at other sites around Egypt (Ikram 2005; Nicholson 2005; Nicholson et al. 2013; Nicholson et al. 2015). 
The inclusion of human skeletal elements in mummy bundles presumed to be animal in origin is known (Kessler and Nur el-Din 2005). Excavations at Tuna el-Gebel recorded the presence of small numbers of human remains mixed with skeletal elements from birds and rodents in the ibis catacombs dated to the Ptolemaic Period (332-30BC) (von den Driesch et al. 2006).

A mummy bundle recorded as being that of a dog from the Kelsey Museum of Archaeology, University of Michigan revealed the presence of fragmented child bones when radiographed (Wilfong 2015). The Kelsey mummy differs to the one described in this paper as its external appearance is crude and not characteristically 'dog-shaped'. The skeletal contents are jumbled, in contrast to the deliberate placement witnessed in the reported case.

Much speculation surrounds the purpose behind the incorporation of human remains within animal mummy bundles. One possible explanation is that burials with naturally mummified human remains located in the desert margins were exposed over time. These remains were likely to have been accidental inclusions in votive animal mummies, where deceased animal remains were collected from within the sacred landscape of burial enclosures (von den Driesch et al. 2006).

In the reported case, the external appearance of the mummy bundle raised initial concerns, questioning its authenticity. One of the main advantages of CT was the visualisation of a multi-stage wrapping process (Fig. 3a). The identification of a number of distinct wrapping layers by varying compression levels is reported in many ancient mummies (McKnight 2010) and is perhaps the result of a phased production system incorporating multiple embalmers. Such layers and the use of supplementary organic material as seen in the ears (Fig. 3b), confirm that the bundle is most likely to be of ancient origin (McKnight et al. in press). Carbon-14 dating would offer a date range for the artefact; however, due to the 
complete nature of the mummy bundle and its status as a museum artefact, invasive sampling was not considered a viable option.

The German natural historian, Johann Blumenbach, recorded a similar specimen. He commented on why he chose this particular mummy from four presented to him for analysis: 'the one that appeared to differ from the others.....by the very close adhesion of the bandages, from which I had reason to expect some difference in the interior preparation of it' (Blumenbach 1794). Unfortunately, Blumenbach did not record the external appearance of the bundle, other than by giving the dimensions and recording that, proportionate to its size, it seemed heavier than would have been expected. Upon dissection, the bundle was found to contain a human humerus belonging to a child of approximately eight years of age.

Whilst Blumenbach had the advantage of being able to compare the actual contents of the mummy with comparative material where necessary, investigation by imaging alone relies wholly upon the quality of the images obtained. The application of 3D printing technology was successful in this case, and provided additional information to enable accurate identification of human skeletal remains, whilst maintaining the integrity of the mummy bundle.

\section{Conclusions}

The identification of unusual contents within wrapped, mummy bundles is often problematic using imaging alone (McKnight et al. in press). The reported specimen was one such example, where identification, even to taxa, proved inconclusive. This manuscript highlights the combined efficacy of clinical imaging and 3D printing as tools in the identification of skeletal elements within wrapped mummy bundles. This successful application highlights the potential for future work where imaging alone may be inadequate. The 3D replica of the skeletal elements displayed alongside the mummy bundle enables visitors to better 
understand this unique artefact, strengthening the applicability of this technique in a museum context.

\section{Acknowledgements}

The authors would like to thank Tyne and Wear Archives and Museums, in particular Sunderland Museum and Great North Museum: Hancock, for permission to study the mummy and its transportation to Manchester. Sincere thanks to Alex Croom of Tyne and Wear Archives and Museums for supplying the photograph of the mummy. Grateful thanks go to the radiographers at the Central Manchester University Hospitals NHS Foundation Trust (CMFT) for their time and enthusiasm for the project. Imaging costs were funded through a Research Endowment Account held in CMFT and the research was supported by a Research Project Grant from the Leverhulme Trust (RPG-2013-142). Thanks are extended to David Thompson, Loughborough University, for assistance with the production of the 3D printed models, and Prof. Don Brothwell, University of York, and Dr. Pia Nystrom, University of Sheffield, for their assistance with the identification.

\section{References}

Atherton-Woolham, S.D. and McKnight, L.M. 2014. 'Post-mortem restorations in ancient Egyptian animal mummies using imaging'. Papers on Anthropology; 23 (1): 9-17.

Atherton-Woolham, S.D. and McKnight, L.M. 2015. 'Animals as votive offerings in ancient Egypt’. In: McKnight, L.M. and Atherton-Woolham, S.D. eds. Gifts for the Gods: Ancient Egyptian Animal Mummies and the British. Liverpool: Liverpool University Press.

Bibb, R., Eggbeer, D. and Paterson, A. 2015. Medical Modelling: the application of advanced design and rapid prototyping techniques in medicine. Cambridge: Woodhead Publishing Ltd; 35-44, 84-85, 450-457. 
Blumenbach, J.F. 1794. ‘Observations on Some Egyptian Mummies Opened in London’. Philosophical Transactions of the Royal Society of London; 84: 177-195.

Chia, H.N. and Wu, B.M. 2015. 'Recent advances in 3D printing of biomaterials'. Journal of Biological Engineering; 9: 4.

D’Auria, S.H. and Marx, H. 1988. ‘Three-Dimensional CT Reconstructions of an Ancient Human Egyptian Mummy’. American Journal of Radiology; 150: 147-149.

Du Plessis, R., Slabbert, L.C., Swanepoel, J., Els, G., Booysen, J., Ikram, S. and Cornelius, I. 2015 'Three-dimensional model of an ancient Egyptian falcon mummy skeleton', Rapid Prototyping Journal 21.4.

Glasser, O. 1933. Wilhelm Conrad Röntgen and the Early History of the Roentgen Rays. London: Bale.

Hoffman, H., Torres, W.E. and Ernst, R.D. 2002. 'Paleoradiology: Advanced CT in the Evaluation of Nine Egyptian Mummies’. RadioGraphics; 22: 377-385.

Hoppa, R.D., Allard, T.T., Bender, F., Elias, J. and Gill-Robinson, H. 2006. 'Using Image Analysis Software to Create a Physical Skull Model for the Facial Reconstruction of a Wrapped Akhmimic Mummy'. Journal of Computing and Information Technology; 14 (1): 45-51.

Ikram, S. and Iskander, N. 2002. Catalogue Général of Egyptian Antiquities in the Cairo Museum: Nos.24048-24056; 29504-29903 (selected); 51084-51101; 61089 Non Human Mummies. Cairo: Supreme Council of Antiquities Press.

Ikram, S. 2013. 'Man’s best friend for eternity: dog and human burials in ancient Egypt'. Anthropozoologica; 48 (2): 299-307. 
Ikram, S., Nicholson, P., Bertini, L. and Hurley, D. 2013. 'Killing Man’s Best Friend?’. Archaeological Review from Cambridge; 28 (2): 48-66.

Ikram, S. 2005. 'Divine Creatures: Animal Mummies’. In: Ikram, S. ed. Divine Creatures: Animal Mummies in Ancient Egypt. Cairo: American University in Cairo Press; 1-15.

Jackowski, C., Bolliger, S. and Thali, M.J. 2008. 'Common and Unexpected Findings in Mummies from Ancient Egypt and South America as Revealed by CT'. RadioGraphics; 28: $1477-1492$.

Kessler, D. and Nur el-Din, A. 2005. 'Tuna al-Gebel: Millions of Ibises and Other Animals'. In: Ikram, S. ed. Divine Creatures: Animal Mummies in Ancient Egypt. Cairo: American University in Cairo Press; 120-163.

Lv, H., Zhang, L., Yang, F., Li, M., Yin, P., Su, X., Yin, P, Zhang, L. and Tang, P. 2015. 'A novel 3D-printed device for localization and extraction of trabeculae from human femoral heads: a comparison with traditional visual extraction'. Osteoporosis International; 26 (6): 1791-9.

McKnight, L. M. 2010. Imaging Applied to Animal Mummification in Ancient Egypt. BAR International series 2175. Oxford: Archaeopress.

McKnight, L.M. and Atherton-Woolham, S.D. 2015. Gifts for the Gods: Ancient Egyptian Animal Mummies and the British. Liverpool: Liverpool University Press.

McKnight, L.M., Atherton-Woolham, S.D. and Adams, J.E. In press. 'Imaging of Ancient Egyptian Animal Mummies’. RadioGraphics.

McKnight, L.M. and Atherton, S.D. 2014. 'How to 'pigeon-hole' your mummy - a proposed categorization system for ancient Egyptian wrapped animal remains based on radiographic 
evaluation’. In: Gill-Frerking, H., Rosendahl, W., Zink, A. and Alterauge, A. eds. Yearbook of Mummy Studies 2. Munich: Verlag Dr. Friedrich Pfeil; 109-116.

Moodie, R.L. 1931. Roentgenologic Studies of Egyptian and Peruvian Mummies. Chicago: Field Museum of Natural History.

Moshenska, G. 2013. ‘Unrolling Egyptian mummies in nineteenth-century Britain’. British Journal of the History of Science; 1-27.

Murphy, S.V. and Atala, A. 2014. ‘3D bioprinting of tissues and organs’. Nature Biotechnology; 32 (8):773-85.

Nicholson,P.T., Ikram, S. and Mills, S. 2015. 'The Catacombs of Anubis at North Saqqara'. Antiquity; 89: 645-661.

Nicholson, P.T., Harrison, J., Ikram, S., Earl, E. and Qin, Y. 2013. ‘Geoarchaeological and environmental work at the Sacred Animal Necropolis, North Saqqara, Egypt’. Studia Quaternaria; 30 (2): 83-89.

Nicholson, P.T. 2005. 'The Sacred Animal Necropolis at North Saqqara: The Cults and Their Catacombs’. In: Ikram, S. ed. Divine Creatures: Animal Mummies in Ancient Egypt. Cairo: American University in Cairo Press; 44-71.

Niven, L., Steele, T.E., Finke, H., Gernat. T. and Hublin, J.J. 2009. 'Virtual skeletons: using a structured light scanner to create a 3D faunal comparative collection'. Journal of Archaeological Science; 36 (9): 2018-2023.

Osborn, D.J. and Osbornova, J. 1998. The Mammals of Ancient Egypt. Warminster, Wiltshire: Aris and Phillips Ltd; 75-80. 
Raven, M.J. and Taconis, W.K.E. 2005. Egyptian Mummies: radiological atlas of the collections in the National Museum of Antiquities in Leiden. Turnhout, Belgium: Brepols.

Schievano, S., Migliavacca, F., Coats, L., Khambadkone, S., Carminati, M., Wilson, N., Deanfield, J.E., Bonhoeffer, P. and Taylor, A.M. 2007. 'Percutaneous Pulmonary Valve Implantation Based on Rapid Prototyping of Right Ventricular Outflow Tract and Pulmonary Trunk from MR Data’. Radiology; 242: 490-497.

Schilling, R., Jastram, B., Wings, O., Schwarz-Wings, D. and Issever, A.S. 2014. 'Reviving the Dinosaur: Virtual Reconstruction and Three-dimensional Printing of a Dinosaur Vertebra’. Radiology; 270 (3): 864-871.

Spring, A.P. and Peters, C. 2014. 'Developing a low cost 3D imaging solution for inscribed stone surface analysis’. Journal of Archaeological Science; 52: 97-107.

Taylor, J.H. 2001. Death and the Afterlife in Ancient Egypt. London: British Museum Press.

Taylor, J.H. and Antoine, D. 2014. Ancient lives: new discoveries - eight mummies, eight stories. London: British Museum Press.

Vanlathem, M.P. 1983. Cercueils et Momies de l'Egypte Ancienne. Brussels: Musée Royaux d'Art et d'Histoire.

Von den Driesch, A., Kessler, D., Steinmann, F., Berteaux, V., Peters, J. 2006. 'Mummified, deified and buried at Hermopolis Magna - the sacred birds from Tuna el-Gebel, Middle Egypt’. Ägypten und Levante: International Journal of Egyptian Archaeology and Related Disciplines; XV: 203-244. 
Von den Driesch, A., Kessler, D. and Peters, J. 2004. 'Mummified Baboons and other Primates from the Saitic-Ptolemaic Animal Necropolis of Tuna el-Gebel'. Documenta archaeobiologiae: Conservation policy and current research. 2004; 2: 231-278.

Wade, A.D., Gregory, J., Garvin, M.D., Hurnanen, J.H., Williams, L., Lawson, B., Nelson, A.J., Tampieri, D. 2012. 'Multidetector CT of Egyptian Mummies of the Redpath Museum'. RadioGraphics; 32: 1235-1250.

Wilfong, T. 2015. Death Dogs. Michigan: Ann Arbor, University of Michigan. 